\title{
Synthesis and characterization of Cadmium (II) complex with tetradentate N2O2- donor Schiff base and biological activity
}

\author{
Animesh Patra ${ }^{1}$, Gobinda Prasad Sahoo ${ }^{1}$, Palash Setua ${ }^{2}$, Akhil Pandey $^{3}$, Surajit Maiti ${ }^{1,2}$ \\ ${ }^{1}$ Postgraduate Department of Chemistry, Midnapore College (Autonomous), Vidyasagar University, India \\ ${ }^{2}$ Departments of Chemistry, Pingla Thana Mahavidyalaya, Vidyasagar University, India \\ ${ }^{3}$ Department of Botany, Midnapore College (Autonomous), Vidyasagar University, India \\ *Corresponding Author: animeshpatrarl@yahoo.com Mobile: 919647309536
}

Available online at: www.isroset.org

Received: 12/Jan/2019, Accepted: 20/Feb/2019, Online: 28/Feb/2019

\begin{abstract}
Transition metal complex of Cd (II) with tetradentate schiff base derived from the condensation of 4-nitro-1,2diamino benzene and 5-nitro-salicyldehyde (H2L) have been synthesized. The synthesized square planar complex was investigated using elemental analysis $(\mathrm{C}, \mathrm{H}$ and $\mathrm{N})$, infrared, conductivity and electronic spectroscopic tools. The interactions of cadmium (II) complex examined towards Bovine serum albumin (BSA) with the help of absorption and fluorescence spectroscopic tools. The complex is strongly binds to proteins, then we study the antibacterial activity of the Schiff base and its cadmium complex by agar disc diffusion method against some species of pathogenic bacteria (Escherichia coli, Vibrio cholerae, Streptococcus pneumonia and Bacillus cereus).The result indicated that cadmium complex was more activity than ligand due to higher lipophilicity effect.
\end{abstract}

Keywords-Cadmium complex, Bovine serum albumin interaction, antibacterial activity.

\section{INTRODUCTION}

Tetradentate Schiff bases with N,N,O,O- donor atoms set are well known to coordinate with various metal ions and this has attracted the interest of many authors [1]. Schiff bases are important intermediates in an enzymatic reactions involving interaction of the amino group of an enzyme, usually lysine residue, with a carbonyl group of the substrate. Complexes of Schiff base ligands have been studied for their dioxygen uptake and oxidative catalysis. Furthermore, complexes of transition metals (II), which involve derivatives of salicyldehyde and diamine have received considerable attention [2]. This is because of their potential as catalysts for the insertion of oxygen into an organic substrate. Schiff bases and their metal complexes have been prepared because of their interesting and important properties, e.g, ability to bind toxic and heavy metal atoms, undergo tautomerism, exhibit catalytic reduction and phototropism[3]. The role of the metal-Schiff base complexes in such applications is related to molecular structure. Thus, it is quite important to have a good understanding of the structure of such metal complexes [4].

The serum albumins are the major soluble protein constituent of the circulatory system because their ability to bind reversibly a large variety of compounds as a depot and a transport protein [5]. The affinities of drugs to proteins would directly influence the concentration of drugs in the blood, binding sites and consequently contribute to their magnitude of biological actions in vivo [6]. In this respect, the present study aimed to investigate the reaction of tetra dentate Schiff bases derived from the condensation of 5nitro-salicyldehyde with 4-nitro-1,2-diamino benzene. The complex was prepared by the equimolar ratio of ligand with metal (II) acetate. The BSA protein binding study of the cadmium (II) complex has been performed spectroscopically. The antibacterial activity of the Schiff base and cadmium (II) complex examined by agar disc diffusion method against some species of pathogenic bacteria (Escherichia coli, Vibrio cholerae, Streptococcus pneumonia and Bacillus cereus).

\section{MATERIALS AND METHODS}

Materials and Instruments: All chemicals and reagents were obtained from commercial sources and used as received, unless otherwise stated. Solvents were distilled from an appropriate drying agent. The organic moieties were synthesized following the procedure. The elemental $(\mathrm{C}, \mathrm{H}$, $\mathrm{N}$ ) analyses were performed on a Perkin Elmer model 2400 elemental analyzer. Cadmium analysis was carried out by Varian atomic absorption spectrophotometer (AAS) modelAA55B, GTA using graphite furnace. Electronic absorption spectra were recorded on a SHIMADZU UV-1800 spectrophotometer. The fluorescence spectra of albumins were obtained in the Fluorimeter (Hitachi-2000). IR spectra (KBr discs, 4000-400 $\mathrm{cm}^{-1}$ ) were recorded using a PerkinElmer FTIR model RX1 spectrometer. Molar conductances 
(M) were measured in a systronics conductivity meter 304 model using $\sim 10^{-3} \mathrm{~mol} \mathrm{~L}^{-1}$ solutions in DMF solvent. The stock solutions of proteins $\left(1.00 \times 10^{-5} \mathrm{~mol} \mathrm{~L}^{-1}\right)$ were prepared by dissolving the solid BSA in $0.05 \mathrm{M}$ phosphate buffer at $\mathrm{pH} 7.4$ and stored at $0-4{ }^{\circ} \mathrm{C}$ in the dark.

Preparation of the ligand (H2L): Synthesize the ligand H2L (Scheme 1) by placing $10 \mathrm{~mL}$ of $95 \%$ ethanol in a Round bottle that also has a small magnetic stirring bar. Heat the ethanol to boiling while stirring. Immediately, with continued heating and stirring, add $1.336 \mathrm{~g}(8.0 \mathrm{mmol})$ of 5nitro Salicyldehyde and then added $0.612 \mathrm{~g}(4.0 \mathrm{mmol})$ of 4 nitro 1,2-diamino benzene, Stir the solution for 3 hour and then reflux up to 2 hour and kept over one night to get the precipitate of the orange ligand. The precipitate was filter by filter paper using vacuum pump and washed several times using ethanol, followed by crystallization in ethanol and dry the crystals as much as possible on the filter using vacuum, and then collected the solid compound.

$\mathrm{C}_{20} \mathrm{H}_{13} \mathrm{~N}_{5} \mathrm{O}_{8}$ : Anal. Found: C, 53,46; H, 2.84; N, 15.68; Calc.: C, 53.21; H, 2.88; N, 15.52, m.p. $196 \pm 1{ }^{\circ} \mathrm{C}$; IR $\left(\mathrm{KBr}, \mathrm{cm}^{-1}\right)$ : $v_{\mathrm{O}-\mathrm{H},}, 3448, v_{\mathrm{NO} 2}, 1342, v_{\mathrm{CH}=\mathrm{N}}, 1618$; Yield: $90 \%$.

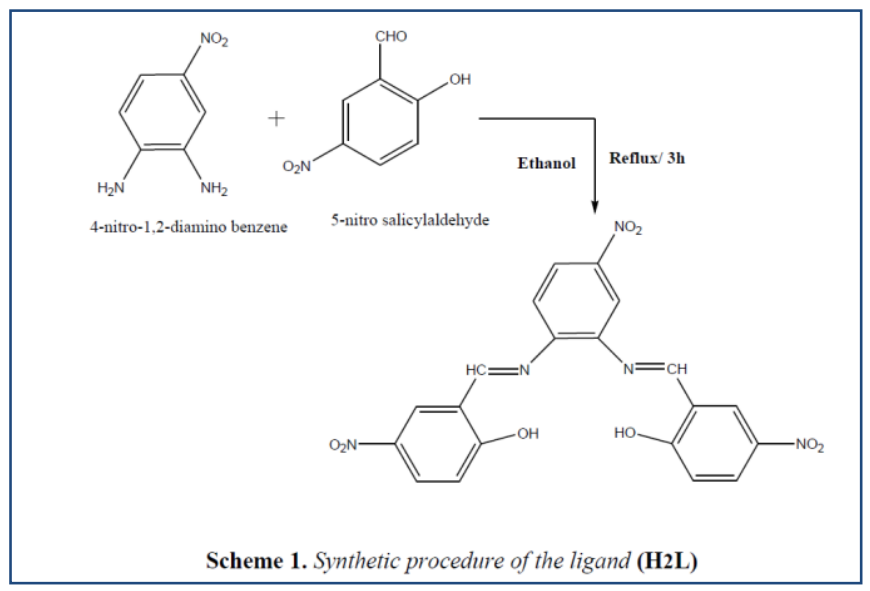

Preparation of $[\mathbf{C d}(\mathbf{L})]$ : To prepare this complex a common procedure, a methanolic solution of $\mathbf{H} 2 \mathbf{L}$ (451 mg, 1.0 mmol) was mixed with $1.0 \mathrm{mmol}$ of Cadmium acetate in equimolar ratio (1:1), stirring condition and the mixture was refluxed for $4 \mathrm{~h}$. The red product was collected by filtration and washing with cold methanol and water and dried in vacuo.

$\left[\mathrm{C}_{20} \mathrm{H}_{11} \mathrm{~N}_{5} \mathrm{O}_{8} \mathrm{Cd}\right]$ : Anal.Found; $\mathrm{C}, 42.84 ; \mathrm{H}, 1.95 ; \mathrm{N}, 12.58$; Cd, 8.58; Calc: C, 42.75; H, 1.95; N, 12.46; Cd, 8.55. IR $\left(\mathrm{cm}^{-1}\right): v_{\mathrm{CH}=\mathrm{N}}, 1613 ; v_{\mathrm{NO} 2}, 1344, v_{\mathrm{M}^{-} \mathrm{N}}, 548, v_{\mathrm{M}-\mathrm{O}}, 477$ m.p. $212 \pm 1{ }^{\circ} \mathrm{C} ; \Lambda_{\mathrm{M}}(\mathrm{DMF}): 14.16 \mathrm{~cm}^{2} \Omega^{-1} \mathrm{M}^{-1}$.

Antimicrobial Screening: The antibacterial activities of the ligand (H2L) and its Cd (II) complex-1 have been studied by agar disc diffusion method [7-8]. The antibacterial activities were done DMF solvent by using three pathogenic gram negative bacteria (Escherichia coli, Vibrio cholerae, Streptococcus pneumoniae) and one gram positive pathogenic bacteria (Bacillus cereus). The solution of ligand and its Cd (II) complex was added to the agar plates. The DMF solvent was used as a negative control. Incubation of the plates was done at $37^{\circ} \mathrm{C}$ for 24 hours, inhibition of the organisms was measured and used to calculate mean of inhibition zones in millimetres.

\section{RESULTS AND DISCUSSION}

Synthesis and characterization of H2L and $\mathrm{Cd}$ (II) complex: The organic ligand $(\mathbf{H} 2 \mathbf{L}=2,2$ '-(4-nitro-1,2phenylene)bis(azan-1-yl-1-ylidene)bis(methan-1-yl-1-

ylidene)bis(4-nitrophenol), was synthesized by the reaction of the respective of 5-nitro Salicyldehyde and 4-nitro 1,2diamino benzene in presence of Ethanol. The complex was obtained in good yield from the reaction of the Cadmium acetate (1) with equimolar amount of respective organic moiety H2L in the methanol medium. In this complex the organic molecule $\mathbf{H 2 L}$ act as tetradentate ligand through NNOO- donor centers and form square planar geometry. The complex conductivity measurement in dimethylformamide shows conductance values suggest that complexes exist in solution as non-electrolyte. This complex is air-stable, nonhygroscopic, coloured solids, partly soluble in ethanol and methanol, and soluble in DMSO and DMF and are monomeric in nature.

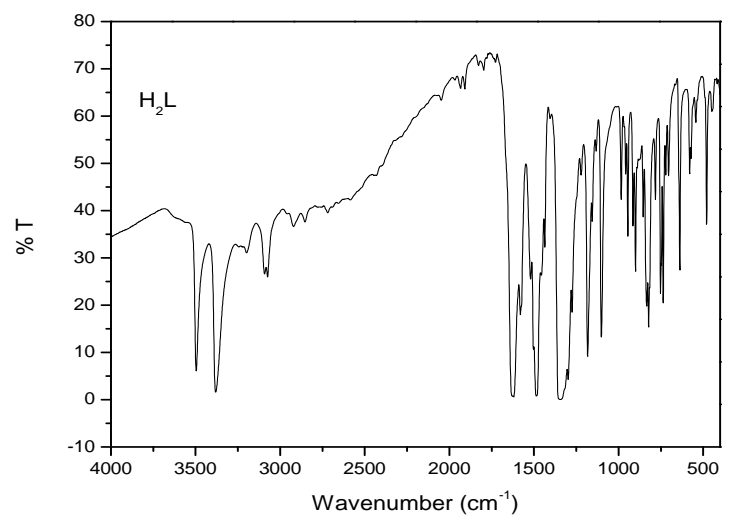

Figure 1. IR spectrum of H2L Ligand

Infrared and Electronic spectral studies: Infrared spectral data of the Schiff base (Figure 1) shows several bands at $3320-3490,1342$ and $1618 \mathrm{~cm}^{-1}$ due to phenolic O-H group, nitro group and imine $\mathrm{CH}=\mathrm{N}$ stretching vibrations in the solid state. These bands are shifted to lower frequency on complexation with $\mathrm{Cd}(\mathrm{II})$ complex. New vibrations at 477 and $548 \mathrm{~cm}^{-1}$ which are not present in the free Schiff base are attributed to the existence of $v(\mathrm{M}-\mathrm{O})$ and $v(\mathrm{M}-\mathrm{N})$. The appearance of these vibrations confirmed the involvement of nitrogen and oxygen atoms in chelation with metal ions. 
The spectra of the Schiff base H2L exhibit three main peaks: at 296.0, 340.0 and $428.0 \mathrm{~nm}$. The first and second peaks were attributed to benzene $\pi \rightarrow \pi^{*}$ and imino $\mathrm{n} \rightarrow \pi^{*}$ transitions, respectively. All the spectra of complex lower bands than $400 \mathrm{~nm}$ are due to intramolecular $\pi \rightarrow \pi^{*}$ and $\mathrm{n}$ $\rightarrow \pi^{*}$ transitions. The electronic spectrum of the $\mathrm{Cd}(\mathrm{II})$ complex shows an absorption band at $456 \mathrm{~nm}$ attributed to the $\mathrm{L} \rightarrow \mathrm{M}$ (charge transfer) transition.

\section{Protien (Bovine serum albumin) binding experiments by absorption spectroscopy:}

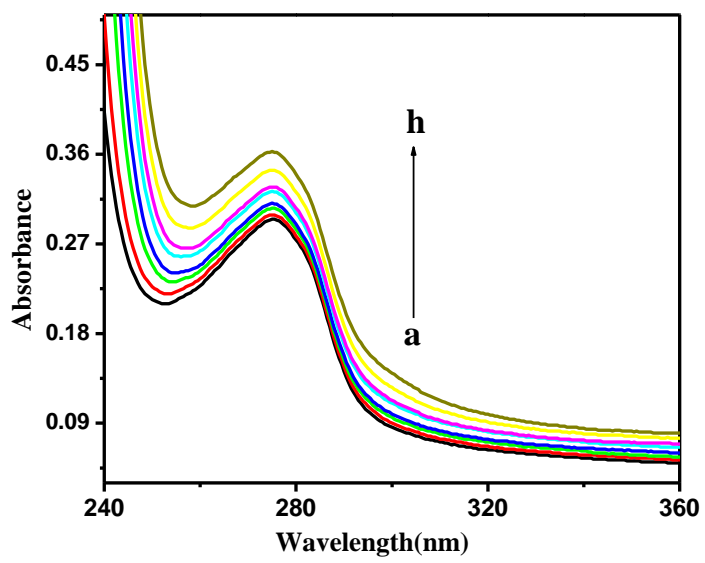

Figure 2. Electronic spectral titration of Cadmium complex with $\mathrm{BSA}$ at $280 \mathrm{~nm}$ in tris-HCl buffer. Arrow indicates the direction of change upon the increase of BSA concentration.

The absorption spectra of BSA in the absence and presence of $\mathrm{Cd}(\mathrm{II})$ complex $\mathbf{1}$ at different concentrations were studied.(Figure 2) From this study we observed that upon increasing the concentration of the complex the absorption of BSA increases regularly[9,10]. The Characteristic peaks in the region of tyrosine and tryptophan absorption indicated perturbation of these chromophores by the binding of metal ions. In other words, metal ions binding to BSA make a slight change in the secondary structure of BSA. From these data the apparent association constant $\left(\mathrm{K}_{\mathrm{app}}\right)$ determined of the complexes with BSA has been determined using the Benesi-Hildebrand equation [11]. $\left.\mathrm{A}_{0}\right)$ [comp]

$$
1 /\left(\mathrm{A}_{\mathrm{obs}}-\mathrm{A}_{0}\right)=1 /\left(\mathrm{A}_{\mathrm{c}}-\mathrm{A}_{0}\right)+1 / \mathrm{K}_{\mathrm{app}}\left(\mathrm{A}_{\mathrm{c}}-\right.
$$

Where, $A_{o b s}$ is the observed absorbance of the solution containing different concentrations of the complex at 280 $\mathrm{nm}, \mathrm{A}_{0}$ and Ac are the absorbances of BSA and the complex at $280 \mathrm{~nm}$, respectively, with a concentration of complex, and $\mathrm{K}_{\text {app }}$ represents the apparent association constant. The linear relationship between $1 /\left(\mathrm{A}_{\mathrm{obs}}-\mathrm{A}_{0}\right)$ vs reciprocal concentration of the complex with a slope equal to $1 / \mathrm{K}_{\mathrm{app}}\left(\mathrm{A}_{\mathrm{c}}\right.$ - $\left.A_{0}\right)$ and an intercept equal to $1 /\left(A_{c}-A_{0}\right)$. The value of the apparent association constant $\left(\mathrm{K}_{\mathrm{app}}\right)$ determined from this plot is $4.26 \times 10^{4} \mathrm{M}^{-1}(\mathrm{R}=0.9682$ for four points $)$.

Fluorescence quenching of BSA by the cadmium complex: The interaction of $\mathrm{Cd}$ (II) complex with BSA was studying by the fluorescence emission spectrum with increasing the concentration of the cadmium complex [12]. The emission spectra of BSA in presence of different concentrations of complex was recorded in the wavelength range $290-500 \mathrm{~nm}$ by exciting the protein at $280 \mathrm{~nm}$ and represented in Figure 3. As seen, in both cases, with increasing the concentration of the cadmium complex the fluorescence intensities of the proteins are regularly decreased. The fluorescence quenching is described by the Stern-Volmer relation [13]

$$
\mathrm{F}_{0} / \mathrm{F}=1+\mathrm{K}_{\mathrm{sv}}[\mathrm{Q}]
$$

Where $\mathrm{F}_{0}$ and $\mathrm{F}$ represent the fluorescence intensities in the absence and presence of quencher respectively. $\mathrm{K}_{\mathrm{sv}}$ is a linear Stern-Volmer quenching constant, $\mathrm{Q}$ is the concentration of quencher. The $\mathrm{K}_{\mathrm{sv}}$ value calculated from the plot of $\mathrm{F}_{0} / \mathrm{F}$ versus [Q] and the $\mathrm{Ksv}$ is $3.68 \times 10^{5} \mathrm{M}^{-1}(\mathrm{R}=0.9764)$. The Stern-Volmer plot represents a good linear relationship and indicating a strong affinity of the cadmium (II) complex to BSA.

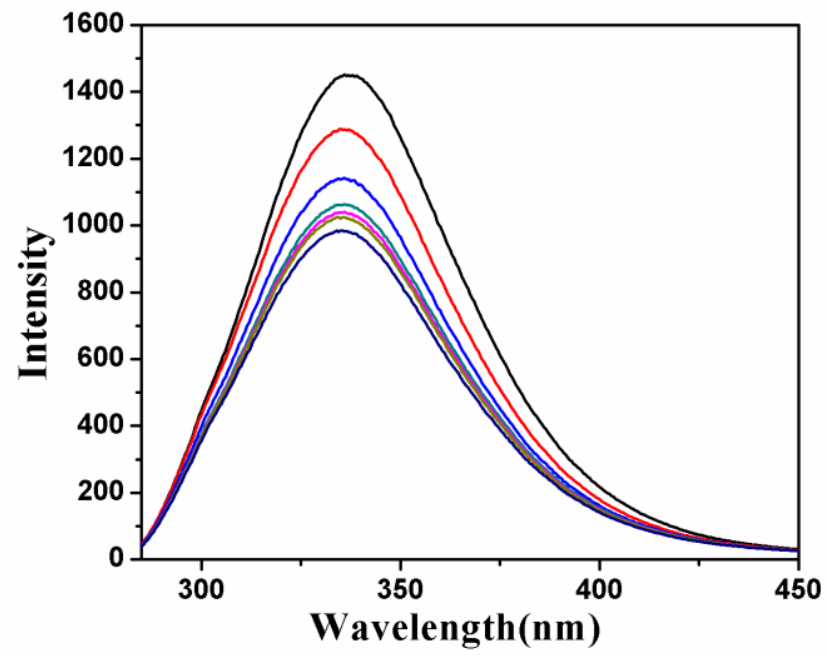

Figure 3. Change in fluorescence spectra of BSA through their titration with complex $\mathbf{1}$. The concentration of complex varied from (a) 0.0 to $(\mathrm{g}) 4.0 \times 10^{-6} \mathrm{M} \mathrm{L}^{-1}$; Eexcitation $=280 \mathrm{~nm}$ and $\mathrm{pH} 7.4$.

Antibacterial activity: Antibacterial activity of the ligand (H2L) and its cadmium (II) complex-1 was shown in Figure 4. Comparison the biological activity of the synthesized ligand and its cadmium (II) compound with standard antibiotic Chloramphenicol $[14,15]$. From the antibacterial studies it is inferred that, complex has higher activity than ligand. The increased activity of the metal chelates can be 
explained by overtone concept and the Tweedy chelation theory. In a complex, increases the delocalization of $\pi$ electrons over the whole chelate ring and increase the lipophilicity character of the metal complexes. This increased lipophilicity also helps the penetration of the bacterial cell membranes and blocks the metal binding sites in enzymes of microorganisms and restricts further growth of the microorganisms. Due to higher lipophilicity, Complex exhibits good antibacterial activity.

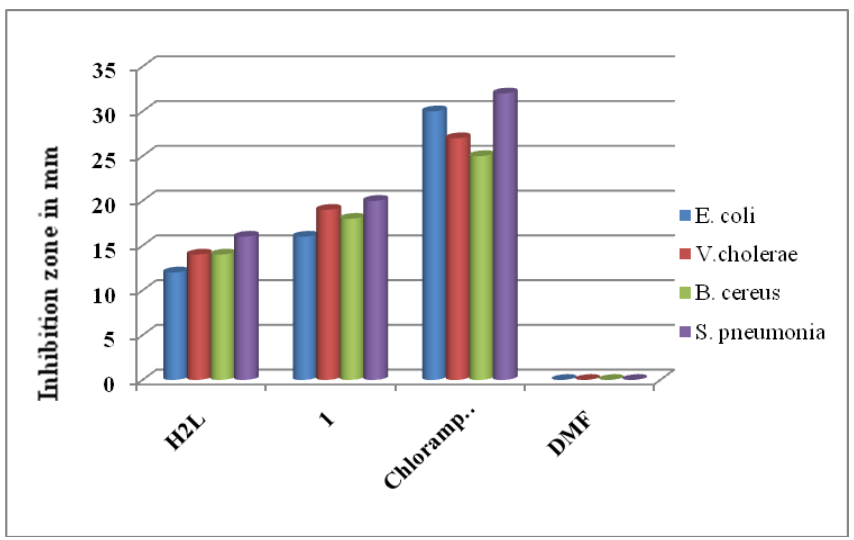

Figure 4. Comparison of the antibacterial activities of $\mathbf{H 2 L}$, Cadmium complex-1 with standard chloramphenicol drug. DMF solvent does not show any activity.

\section{CONCLUSION}

Synthesis and characterization of square planar cadmium (II) complex of $\mathrm{N} 2 \mathrm{O} 2$ donor set have been performed by various spectrochemical tools. The binding mechanisms of cadmium (II) complex interacting with BSA were investigated by spectroscopic methods. Experimental values suggested that the $\mathrm{Cd}(\mathrm{II})$ complex strongly bind with BSA protein. The biological significance of this work is evident since albumin serves as an endogenous carrier for the complex in the body, which could be a useful guide for further drug design. The antimicrobial studies data reveal that the cadmium complex acts as more bactericidal agents as compared to the uncomplexed Schiff base ligand due to higher lipophilicity.

\section{ACKNOWLEDGMENT}

We gratefully acknowledge the financial support from UGC minor research project [F.No.PSW-142/14-15 (ERO)] and F. No. PSW-230/15-16(ERO), India.

\section{REFERENCES}

[1] Chakraborty, A., Kumar, P., Ghosh, K., Roy, P., Evaluation of a Schiff base copper complex compound as potent anticancer molecule with multiple targets of action, 2010. Eur J Pharmacol, 647, 1-12.

[2] Keypour, H., Shayesteh, M., Rezaeivala, M., Chalabian, F., Elerman, Y., Buyukgungor, O., Synthesis, spectral characterization, structural investigation and antimicrobial studies of mononuclear $\mathrm{Cu}(\mathrm{II}), \mathrm{Ni}(\mathrm{II})$, $\mathrm{Co}(\mathrm{II}), \mathrm{Zn}(\mathrm{II})$ and $\mathrm{Cd}(\mathrm{II})$ complexes of a new potentially hexadentate N2O4 Schiff base ligand derived from salicylaldehyde. 2013. J.Mol. Structure, 1032, 62-68.

[3] Konar, S., Jana, A., Das, K., Ray, S., Chatterjee, S., Golen, J.A., Rheingold, A.L., Kar, S.K., Synthesis, crystal structure, spectroscopic and photoluminescence studies of manganese(II), cobalt(II), cadmium(II), zinc(II) and copper(II) complexes with a pyrazole derived Schiff base ligand. 2011. Polyhedron, 30, 28012808.

[4] Cordes, E.H., Jencks, W.P., On the Mechanism of Schiff Base Formation and Hydrolysis. 1962. J. Am. Chem. Soc, 84, 832-837.

[5] Asadi, M., Sadi, S.B., Asadi, Z., Yousefi, R., Sadi, A.R.B., Hezarjaribi, H.K., Synthesis, characterization, and thermodynamic studies of the interaction of some new water-soluble Schiff-base complexes with bovine serum albumin. 2012. J. Coord. Chem. 65, 722-739.

[6] Carter, D.C., Ho, J.X., Structure of Serum Albumin. 1994. Adv. Protein Chem. 45, 153-203.

[7] Mann, C.M., Markham, J.L., 1998. A new method for determining the minimum inhibitory concentration of essential oils. J. Appl. Microbiol, 84, 538-544.

[8] Baba1, D. R., Junaid, P. M., Khan, F., Singh, R., Nitric Oxide Scavenging Activity of Bioactive Compounds Present in Methanolic Extract of Morchella esculenta. 2018. International Journal of Scientific Research in Biological Sciences. 5, 39-41.

[9] Hazra, M., Dolai, T., Giri, S., Patra, A., Dey, S.K., 2014. Synthesis of biologically active cadmium (II) complex with tridentate $\mathrm{N} 2 \mathrm{O}$ donor Schiff base: DFT study, binding mechanism of serum albumins (bovine, human) and fluorescent nanowires, J. Saudi Chem. Soc. 21, S445-S456.

[10] Gelamo, E.L., Tabak, M., 2000. Spectroscopic studies on the interaction of bovine (BSA) and human (HSA) serum albumins with ionic surfactants. Spectrochim. Acta,Part A, 56, 2255-2271.

[11] Benesi, H.A., Hildebrand, J.H., 1949. A spectrophotometric investigation of the interaction of iodine with aromatic hydrocarbons. J. Am. Chem. Soc. 71, 2703-2707.

[12]Zhang, X.P., Hou, Y.H., Wang, L., Zhang, Y.Z., Liu, Y., 2013. Exploring the mechanism of interaction between sulindac and human serum albumin: Spectroscopic and molecular modeling methods. J. Lumin, 138, 8-14. 
[13] Stern, O.and M. Volmer, 1919. "über die Abklingzeit der Fluoreszenz," Zeitschrift für Physik, 20, 183-188.

[14] Gaballa, A.S., Teleb, S.M., Asker, M.S., Yalçin, E., Seferoğlu, Z., 2011. Synthesis, spectroscopic properties, and antimicrobial activity of some new 5-phenylazo-6aminouracil-vanadyl complexes, J. Coord. Chem. 64, 4225-4243.

[15] Pandeya, S.N., Sriram, D., Nath, G., De Clercq, E., 1999. Synthesis, antibacterial, antifungal and antiviral activity evaluation of some new bis-Schiff bases of isatin and their derivatives. Pharm. Acta Helv. 74, 11-17.

\section{AUTHORS PROFILE}

Dr. A Patra pursed M. Sc. From Vidyasagar University, and Ph.D. (Inorganic Chemistry) from Burdwan University in 2005 \& 2013. $\mathrm{He}$ is currently working as assistant Professor in Department of Chemistry, Midnapore College (Autonomous) since 2009. Dr. G. P. Sahoo pursed M. Sc. and Ph.D. (nano Science) from Vidyasagar University in 2004 \& 2015 . He is currently working as assistant Professor in Department of Chemistry, Midnapore College (Autonomous) since 2007. Dr. P. Setua pursed M. Sc. From Vidyasagar University in 2004 and Ph.D. from IIT. Kharagpur in 2011. He is currently working as assistant Professor in Department of Chemistry, Pingla Thana Mahavidyalaya since 2007. Dr. A. Pandey pursed M. Sc. and Ph.D. from Vidyasagar University in 2009 \& 2017. He is currently working as assistant Professor in Department of Botany, Midnapore College (Autonomous) since 2017. Mr. S. Maiti pursed M. Sc. from Midnapore College (Autonomous) in 2018. 